\title{
WIND-TUNNEL PREDICTION OF WIND POWER PRODUCTION IN COMPLEX TERRAIN
}

\author{
James Cheng ${ }^{*}$, David Lubitz and Bruce R. White \\ Mechanical and Aeronautical Engineering, University of California, Davis \\ One Shields Ave. \\ Davis, CA, USA. 95616 \\ brwhite@ucdavis.edu
}

\begin{abstract}
$\underline{\text { ABSTRACT }}$
An atmospheric boundary layer wind tunnel was used to survey the variation in local wind conditions over a region of the Altamont Pass, California, containing two wind farms. Meteorological data combined with the wind tunnel results were used to predict the power output of the wind farms every half hour over a oneyear period from July 2001 to June 2002. It was observed that the power production of the wind farms could be predicted with $20 \%$ error during the high power production summer months, and $40 \%$ error during the low power production winter months.
\end{abstract}

\section{INTRODUCTION}

The deregulation of the California electricity markets in 1998 posed a great challenge to those in the wind energy business. Under deregulation, wind plant owners and operators expose themselves to high financial risk when they bid to supply real-time and next-day wind energy to the California Independent System Operator (ISO), Power Exchange (PX), and Automated Power Exchange (APX) (McGowin and Pantoya, 1999). Thus, on a day with little wind, a wind plant operator could incur a huge financial loss if they are unable to deliver on their contracts. Accurate wind energy forecasting would provide a way to reduce the financial risk to wind plant operators and to make wind energy a viable alternative to fossil fuels.

With an increasing interest in accurate wind energy forecasting in California, the California Energy Commission established the Wind Energy Forecasting project, a multi-year study. This project, overseen by the Electric Power Research Institute (EPRI 2003a,

\footnotetext{
* Present address: Lawrence Livermore National Laboratory, Livermore, CA, USA.

Copyright (C) 2004 by James Cheng, David Lubitz and Bruce R. White. Published by the American Institute of Aeronautics and Astronautics, Inc. and the American Society of Mechanical Engineers with permission.
}

2003b), was aimed at developing a long range (one to two day) wind power-forecasting tool, in which several organizations participated, and developed several forecasting methods. More importantly, the UC Davis component of the project was a study aimed at developing an accurate wind energy forecasting methodology by incorporating wind tunnel data and a forecasting algorithm for a specific wind farm. The first phase of this study, a wind-tunnel investigation of an Altamont Pass wind-farm site, is presented here. In the future, the results of this study will be incorporated into a site-specific wind power forecasting system.

\section{BACKGROUND}

Under neutral conditions, the atmospheric or planetary boundary layer depth varies from $300 \mathrm{~m}$ to $2000 \mathrm{~m}$. In the atmospheric boundary, wind turbines generally operate within the surface layer, typically the lowest 50 to 100 meters, and are often situated at elevated positions, such as in mountainous terrains or on ridges. As a result, the effects of terrain on wind energy output can be substantial. Most analytical equations for determining velocity profiles were developed mainly for flat and homogenous surface conditions. However, work has been done on wind speed-up over twodimensional hills (Miller and Davenport, 1998) and for specific sites such as Askervein and Kettles Hills. Even with three dimensional modeling and field data, it is difficult to apply results from these investigations to other cases of fully three-dimensional complex terrain.

A portion of the Altamont Pass wind resource area, near Livermore, California, was selected for this particular wind energy prediction study. The site is located about $50 \mathrm{~km}$ east of San Francisco, where wind conditions can be influenced by diurnal sea breezes, and a series of rolling hills that separate the San Francisco Bay area from the San Joaquin Valley. Although no longer the largest wind energy producer, the Altamont Pass still contains one of the world's largest concentrations of wind turbines. 
The winds in the Altamont Pass area are strongest during the summer, and lowest during the winter. For a site approximately $1 \mathrm{~km}$ from the Tower A site tested in this study, Davis and Nierenberg (1980) observed a monthly average wind speed of $23.0 \mathrm{mph}$ during July, 1979, versus $7.3 \mathrm{~m} / \mathrm{sec}$ for December 1979 . The level of seasonal variation was similar for several other sites they observed within the Altamont Pass region.

Winds can also vary significantly over relatively short distances due to the effects of complex terrain. Holets (1985) compared observations from eight hilltop sites in the Altamont Pass area, and found significant variation between sites. For 11 summer days in 1981, Holets observed average wind speed differences between the sites of $3.7 \mathrm{~m} / \mathrm{sec}$ to $4.6 \mathrm{~m} / \mathrm{sec}$. Brown and Watt (1988) observed a mean annual wind speed ratio of 0.83 comparing a reference site to a nearby anemometer mast.

As part of a study validating a mass-consistent model, Barnard et al. (1987) reported eight cases of up to 28 simultaneous wind speed measurements within a $4 \mathrm{~km}^{2}$ square region on the eastern slope of the Altamont hills, a few kilometers southeast of the region modeled in this study. Sites ranged from hill- and ridge-tops to valley bottoms. Wind direction at a reference site was between $225^{\circ}$ and $250^{\circ}$ for all eight cases. The ratio of highest over lowest observed wind speeds for each of the eight cases ranged from 1.46 to 2.54, with higher ratios generally being observed at greater stability levels. For the 8 cases, wind speeds at a reference site varied from $8.5 \mathrm{~m} / \mathrm{sec}$ to $18.3 \mathrm{~m} / \mathrm{sec}$. Barnard (1991) also conducted a study using data from August 1985 of a different 6 $\mathrm{km}^{2}$ region of the Altamont Pass with 26 stations positioned in potential high wind locations. The onemonth average wind speeds observed varied from 8.2 $\mathrm{m} / \mathrm{sec}$ for a hillside site to $13.0 \mathrm{~m} / \mathrm{sec}$ for a hilltop site, with wind speeds generally increasing towards the east, due to a downslope flow acceleration that occurs in the Altamont Pass area.

It has also been observed that stable conditions often result in high near-surface wind speeds in the lowest $100 \mathrm{~m}$ above ground (Nierenberg, 1989). McCarthy (1987) observed that a deep marine inversion layer, relative to the height of the pass, often resulted in good (eastern) lee slope flow, while a shallow inversion layer resulted in separation zones on the lee (eastern) slope, and "spotty" flow in general. McCarthy observed that stably stratified flow is an important factor in producing high winds on the less (eastern) slope of the pass.

\section{Wind Tunnel}

The UC Davis Atmospheric Boundary Layer Wind Tunnel (ABLWT) is designed for simulating neutral atmospheric boundary layer flows past surface objects. It is an open-return type tunnel, as seen in Fig. 1, composed of five sections: an entrance section, a flow development section, a test section, a diffuser section and a $56 \mathrm{~kW}(75 \mathrm{hp})$ DC motor and fan. Wind speeds within the tunnel can be varied from 1 to $10 \mathrm{~m} / \mathrm{s}$ ( 2 to $22 \mathrm{mph}$ ). A bell-shaped entrance section provides a small contraction area ratio. An air filter, to screen out airborne particles and reduce the large-scale pressure fluctuations, is followed immediately by a honeycomb flow straightener and a series of spires to "pre-form" the boundary layer.

A $12 \mathrm{~m} \mathrm{(39} \mathrm{ft)} \mathrm{long} \mathrm{flow} \mathrm{development} \mathrm{section} \mathrm{is} \mathrm{used} \mathrm{to}$ generate a mature boundary layer at the test section. An adjustable ceiling and diverging walls in the development section maintain a zero-pressure-gradient flow. Roughness elements are placed on the floor of this section to generate the proper boundary layer height in the test section. The test section is $3.7 \mathrm{~m} \mathrm{(12}$

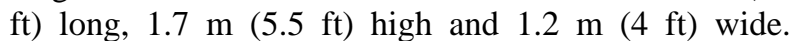
Plexiglas windows on each side allow observation, and a sealed, sliding door is used for_access. Measurements are made using a three-dimensional traversing probe system that is mounted to the ceiling of the test section. This system allows for precise placement of a sensor at any point within the test section. Small $1 \mathrm{~mW}$ lasers were mounted on the traverser to sight vertical height

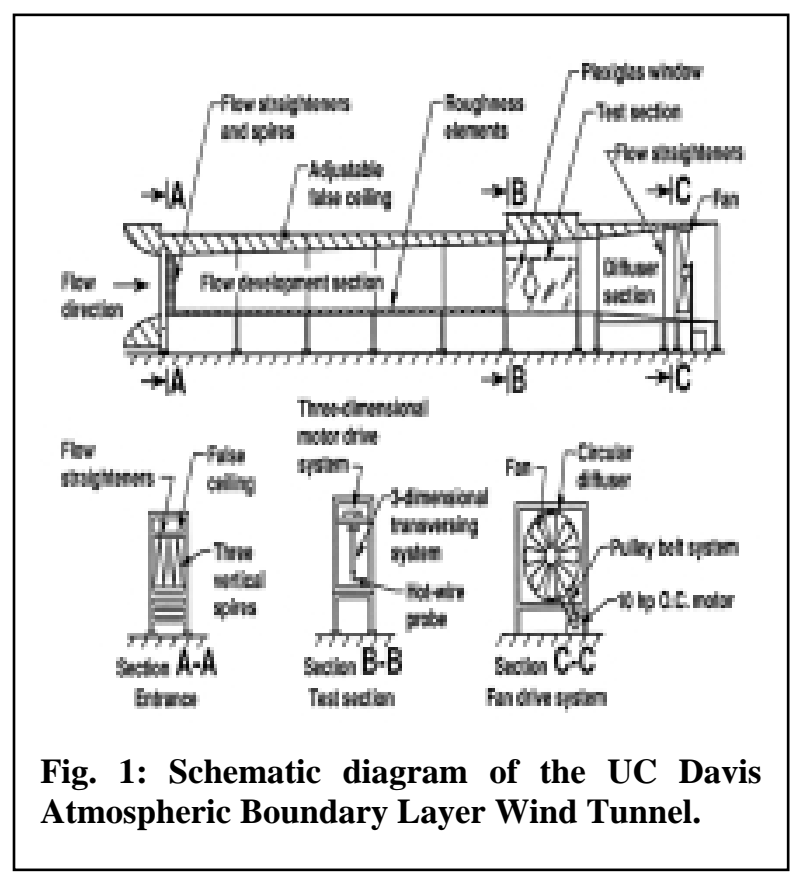


and horizontal position to within $1 \mathrm{~mm}$.

Mean velocity and turbulence intensity were measured using a TSI Inc. single wire, end flow hot-wire probe, Model 1210-20. A 90 angle adapter, TSI Model 1152, was used to provide access to upstream points when attached to an end flow probe. The right angle bend was used to limit the undesirable flow interactions of the model with the probe support by orienting the hot wire directly upwind of its support. A TSI single sensor, plug-in, Model 1150, $50 \mathrm{~cm}$ probe provided support and electrical connection with the signal conditioner.

The probe assembly was secured to the threedimensional traversing system in the test section of the ABLWT. A $10 \mathrm{~m}$ shielded tri-axial cable connects the hot wire to a two-channel constant temperature thermalanemometry unit with a signal conditioner, TSI model IFA 100. The analog signal from the signal conditioner is passed to a 12-bit analog to a digital (A/D) converter (United Electronics Industry Win 30 DS) and then to a Pentium 166 computer for analysis and data storage by a National Instruments LabView program. The A/D conversion process causes no loss in accuracy of the measurement data.

Thermal anemometry has been widely used in measuring turbulent characteristics for its ease in handling fast fluctuations in turbulence. Typically, hotwire measurements made close to the surface have an uncertainty of about $\pm 5 \%$ of the true values.

\section{Wind-tunnel Boundary Layer Characteristics}

The boundary layer within the wind tunnel simulates the same turbulent characteristics found in the full-scale atmospheric boundary-layer. It is important that the atmospheric boundary-layer approaching the modeled region have the same characteristics as it does in fullscale. Otherwise, the changes in local velocity over the model will not be accurately simulated. The region upwind of the modeled terrain is a flat region of the Livermore valley, so it was not necessary to build a specific model of this upwind region.

The relationship between the mean velocity $U$, and height above the surface $z$, for a boundary-layer of height $\delta$ and a mean velocity at height $\delta$ of $U_{\infty}$, is described by the power law:

$$
\frac{U}{U_{\infty}}=\left(\frac{z}{\delta}\right)^{\alpha}
$$

The wind-tunnel power-law exponent $\alpha$ must closely match the full-scale value of $\alpha$. Using the empirical power law estimation methods, from Counihan (1975), and a full-scale surface roughness, $\mathrm{z}_{\mathrm{o}}$ estimated at 15.6 $\mathrm{cm}$, from a wind study done by Chapman and Gouveia (1987), $\alpha$ was estimated to be 0.17 for the approach to Altamont Pass. However, using the empirical method from Jensen (1958), and a geostrophic wind speed, $\mathrm{U}_{\infty}$ of $30 \mathrm{mph}$ and $\delta$ of $457 \mathrm{~m}(1160 \mathrm{ft})$, from meteorological data used in the study, $\alpha$ was estimated to be 0.20 .

Given this range of the power-law exponent $\alpha$, this fullscale condition was achieved in the UC Davis ABLWT by systematically arranging a pattern of 3.5 " x $5.75 " \mathrm{x}$ $0.75 "$ (thin blocks) and 3.25" x 7.75" x 1.5" (thick blocks) wooden blocks over the entire flowdevelopment section of the wind tunnel. The block pattern roughly consisted of half of each type of block configured in alternating sets of four and five blocks per row. A typical mean velocity profile in the wind tunnel is shown in Fig. 2, where the simulated powerlaw exponent $\alpha$ is equal to 0.19 .

In addition, the approaching mean velocity profile should also agree with the logarithmic, or "law-of-thewall," wind profile, within the lower region of the boundary layer:

$$
\frac{U}{U_{\infty}}=\frac{1}{\kappa} \ln \left(\frac{z}{z_{o}}\right)
$$

where $\kappa$ is von Karman constant. The surface layer, the lower 10 to $15 \%$ of the boundary layer, is governed by Eq. (2). For proper wind-tunnel modeling, the model must be geometrically scaled to remain within this bound. From previous data, the simulated atmospheric boundary height of the ABLWT is about $0.7 \mathrm{~m}$, although this will vary over the complex terrain model. Thereby, the lower $20 \%$ within the wind tunnel is 0.14 m. Scaling from wind tunnel to full-scale (1:2400), the atmospheric boundary-layer height becomes about 1680 $\mathrm{m}$, while the lower $20 \%$ is about $336 \mathrm{~m}$. Although the highest elevation in the Altamont Pass is about $457.2 \mathrm{~m}$ $(1500 \mathrm{ft})$, most turbines are situated at about $353 \mathrm{~m}$ $(1160 \mathrm{ft})$, which is within the desired lower $20 \%$ surface-layer region.

Boundary-layer similitude also requires surface roughness Reynolds number, $\mathrm{Re}_{\mathrm{z}}$ independence, in which $\mathrm{Re}_{\mathrm{z}}$ is greater than 2.5 as described by Sutton in 1949. The roughness Reynolds number $\left(\operatorname{Re}_{z}=\right.$ $\left.u_{*} z_{o} / v\right)$, is about 14 when the wind tunnel free-stream 
velocity $\mathrm{U}_{\infty}=3.1 \mathrm{~m} / \mathrm{s}$, friction velocity, $u_{*}=0.22 \mathrm{~m} / \mathrm{s}$, and the roughness height $z_{0}=0.00095 \mathrm{~m}$. Therefore, with $\operatorname{Re}_{\mathrm{z}}$ well above 2.5 , the simulated atmospheric flow is aerodynamically "rough," similar to conditions seen in full-scale conditions.

Lastly, the satisfaction of Jensen's criterion will be limited in this study. Objects in the model are limited to the $2.5 \mathrm{~mm}$ step layers used to build up the complex terrain. In general, the Altamont Pass contains no large objects, vegetation or buildings. However, the key to achieving quality flow in the wind tunnel resides in satisfying the Reynolds number independence criterion. As stated by Snyder (1981), ignoring the Jensen criterion will only limit the resolution of the flow over the model, but with Reynolds criterion met, the overall flow patterns will be matched.

\section{METHOD}

A physical model of an Altamont Pass wind farm, shown in Figs. 3 and 4, owned by Powerworks Inc., was constructed for testing in the UC Davis Atmospheric Boundary Layer Wind Tunnel (ABLWT). The model, seen in 5 was made from high-density foam at a scale of $1: 2400$, modeling a region $2.8 \mathrm{~km}$ long by $8.8 \mathrm{~km}$ long, in which the vertical and horizontal scales of the model are identical. The long axis of the model is oriented to simulate a wind from $240^{\circ}$, the dominant power producing wind direction in this region of the Altamont Pass. The model was built up in $2.5 \mathrm{~mm}$ layers. These "stepped elevations" provide surface roughness to maintain turbulent flow over the model surface. The full-scale peak elevations of the site are about $457.2 \mathrm{~m}(1500 \mathrm{ft})$, while the valleys are at levels of $183 \mathrm{~m}(600 \mathrm{ft})$. The majority of the testing was done on the two downwind sections. Upwind of the model, the terrain transitions to the lower and flatter Livermore valley.

The study wind farm operates Kennetech Model 56-100 horizontal axis turbines, with rotors oriented downwind of the towers. From Fig. 6, the power curve defines the wind turbine power performance as a function of wind speed. A third-order polynomial can be used to fit the curve so that it can be used analytically for the power predictions. The resulting power curve is defined as:

$\mathrm{P}=0: \mathrm{U} \leq 4.9$

$\mathrm{P}=-0.1115 \mathrm{U}^{3}+3.995 \mathrm{U}^{2}-28.203 \mathrm{U}+56.513: 4.9<\mathrm{U}<12.5$

$\mathrm{P}=107.5: \mathrm{U} \geq 12.5$

$\mathrm{P}=0: \mathrm{U}>19.5$ where $\mathrm{U}$ is the wind speed at hub height in $\mathrm{m} / \mathrm{s}$ and $\mathrm{P}$ is the power output of the turbine in kilowatts $(\mathrm{kW})$. Each cluster of wind turbines is associated with a specific meteorological tower. Two meteorological Towers, called A and B, associated with about 90 and 120 turbines respectively, were chosen to be modeled, based on the relatively short distances from the turbines to their meteorological towers. The locations of these meteorological towers and turbines were carefully plotted on the terrain model.

The recorded meteorological and power production data

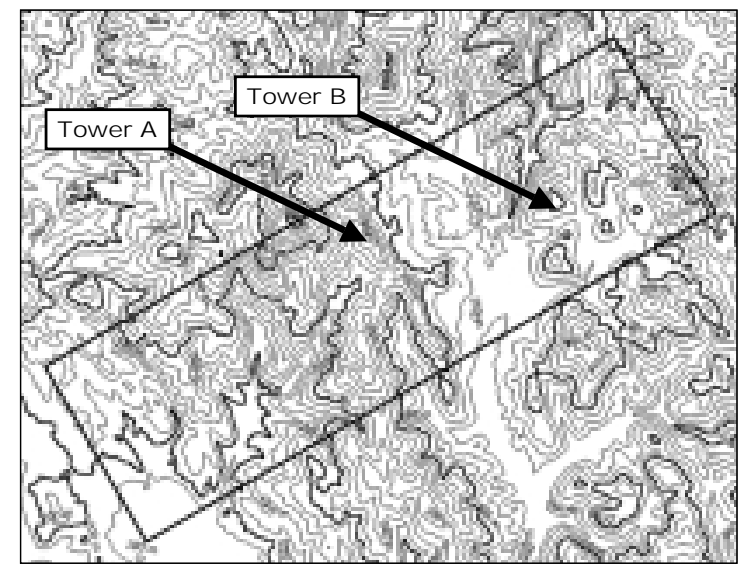

Fig. 3: Contour map of study area. Rectangle outlines the region modeled. Positions of meteorological towers are indicated. Contour interval is $20 \mathrm{~m}$. Region shown is $9.5 \mathrm{~km}$ by $7.5 \mathrm{~km}$.

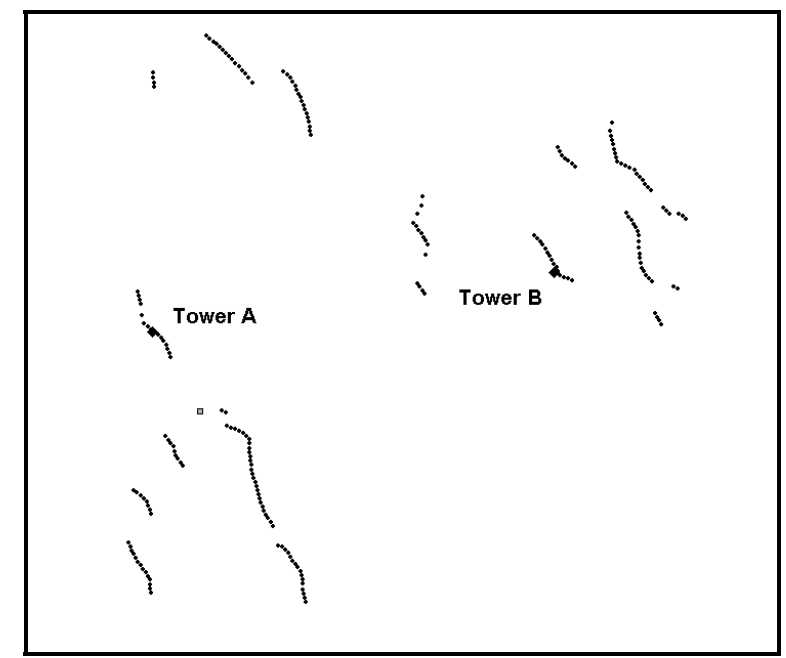

Fig. 4: Positions of wind turbines associated with Towers A and B. (Data from EPRI, 2003b.) 
for the study wind farm was downloaded from a secure FTP server hosted by the Electric Power Research Institute (EPRI). Data was recorded at 30-minute intervals and included: wind speed, maximum wind speed, wind direction, and their respective standard deviations. Additional data included the net power production of the met tower's turbine cluster and operation times of the wind turbines, such as turbine online time, available time, and out of service time. Due to non-disclosure agreements, a sample data set cannot be provided.

\section{Estimation of Full-Scale Winds}

From simulation theory it is known that the ratio of turbine-level wind-speed to a specific meteorological tower wind speed is equivalent. That is, the wind-speed ratios in the wind tunnel are equal to those in full-scale. The reference height used corresponds to the height of the meteorological stations located near each cluster of wind turbines. More specifically, Meteorological tower A and Meteorological tower B have respective heights of $18.3 \mathrm{~m}(60 \mathrm{ft})$ and $24.4 \mathrm{~m}(80 \mathrm{ft})$. Thus, using Eq. (1) and assuming wind-speed ratios are equal to the power-law relationship as given by White (1992), the ratios can be written as:

$$
\left(\frac{\mathrm{U}_{\text {turb }}}{\mathrm{U}_{\text {met }}}\right)_{\text {Full_Scale }}=\left(\frac{\mathrm{U}_{\text {turb }}}{\mathrm{U}_{\text {met }}}\right)_{\text {Wind_Tunnel }}=\left(\frac{\mathrm{z}}{\mathrm{H}_{\text {met }}}\right)^{\alpha}
$$

where $\mathrm{U}_{\text {turb }}$ is the mean wind-speed at hub height $\mathrm{z}$, which varies between $18.3 \mathrm{~m}(60 \mathrm{ft})$ and $24.4 \mathrm{~m}(80 \mathrm{ft})$, $\mathrm{U}_{\text {met }}$ is the mean wind-speed at the meteorological towers at the reference height $\mathrm{H}_{\text {met }}$ which is $18.3 \mathrm{~m}$ for Meteorological Tower A and $24.4 \mathrm{~m}$ for Meteorological Tower B. In determining the estimated full-scale windturbine speed, $\mathrm{U}_{\text {turb, full-scale }}$, the power-law relationship can be re-written in the following form:

$$
\mathrm{U}_{\text {turb }_{\text {Full_Scale }}}=\mathrm{U}_{\text {turb }_{\text {Wind_Tunnel }}}\left(\frac{\mathrm{U}_{\text {met }_{\text {Full_Scale }}}}{\mathrm{U}_{\text {met }_{\text {Wind_Tunnel }}}}\right)
$$

To account for changes in daily conditions within the wind tunnel, a wind-tunnel free stream speed $U_{\infty}$, will be introduced, which yields:

$$
U_{\text {turb:ull_scale }}=\left(\frac{U_{\text {turb }}}{U_{\infty}}\right)_{\text {Wind_Tunnel }} \cdot U_{\text {met Ful__Scale }} \cdot\left(\frac{U_{\infty}}{U_{\text {met }}}\right)_{\text {Wind_Tunnel }}
$$

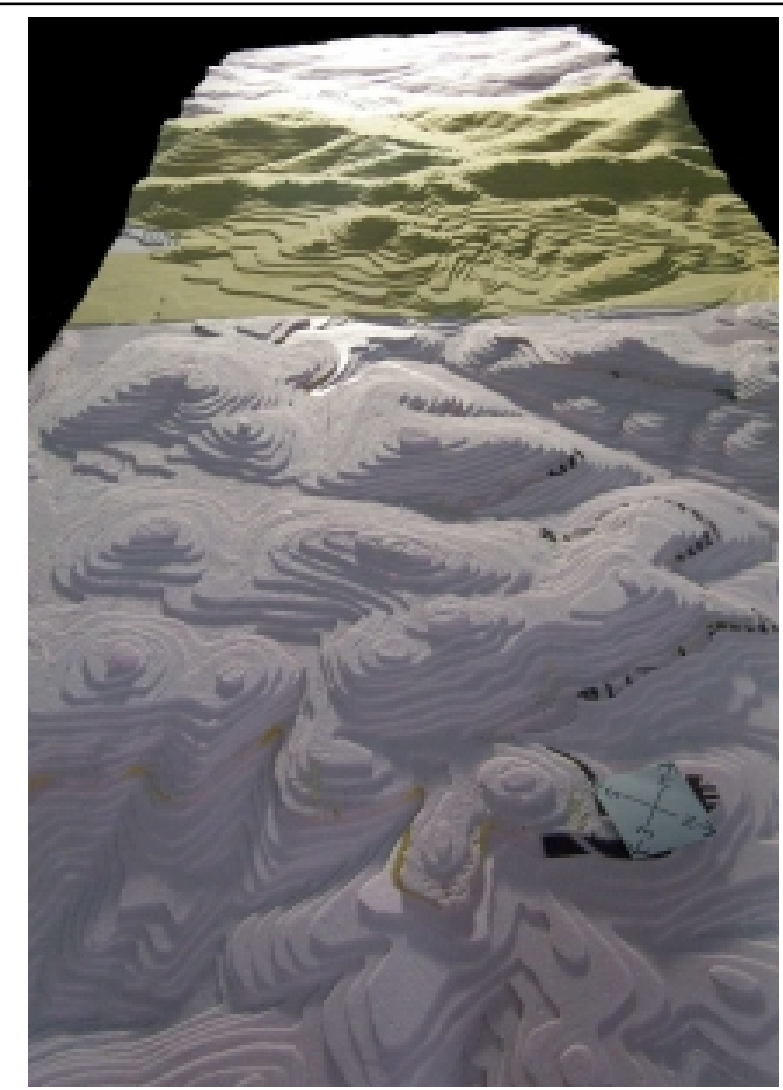

Fig. 5: Terrain model tested in the wind tunnel. Tower A turbine cluster is situated on ridges in center third of model. Tower B turbine cluster is situated on closest third of model. View is in $240^{\circ}$ direction, with the wind traveling towards the viewer.

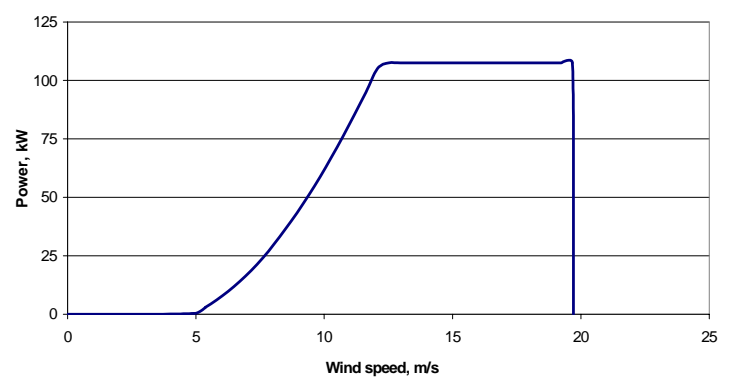

Fig. 6: Power curve of Kennetech 56-100 wind turbine.

where $\left(\mathrm{U}_{\text {turb }} / \mathrm{U}_{\infty}\right)_{\text {Wind-Tunnel }}$ is defined as $\mathrm{R}$, the windtunnel wind-speed ratio. In addition, from measurements taken in the ABLWT, it was found that 


$$
\left(\frac{U_{\infty}}{U_{\text {met }}}\right)_{\text {Wind_Tunnel }}=1.30
$$

In order to assess the legitimacy of the wind-tunnel ratio value of 1.30, a comparison between full-scale and wind tunnel ratios involving free stream or geostrophic wind-speed $\mathrm{U}_{\mathrm{Geostrophic}}$, is as follows:

$$
\left(\frac{U_{\text {ref }}}{U_{\text {Geostrophic }}}\right)_{\text {Full_Scale }}=\left(\frac{z_{\text {ref }}}{\delta}\right)_{\text {Full_Scale }}^{\alpha}
$$

where $\mathrm{z}_{\text {ref }}$ is $353.6 \mathrm{~m}(1160 \mathrm{ft}), \delta$ is the boundary-layer height over the Altamont Pass, estimated at $1767.8 \mathrm{~m}$ $(5800 \mathrm{ft})$, and the power-law exponent $\alpha$ is about 0.19 . As a result,

$$
\left(\frac{U_{\text {ref }}}{U_{\text {Geostrophic }}}\right)_{\text {Full_Scale }}=(0.2)^{0.19}=0.737
$$

which closely matches the results from the wind-tunnel value of 0.769 . However, it is known that the direct comparison between full-scale and wind-tunnel ratios will be somewhat inaccurate. At geostrophic heights in the atmosphere, wind-tunnel ratios tend to break down due to the Coriolis effects that exist in full-scale conditions; however, if comparisons are made within the surface layer, correlation from model to full-scale should remain high. Therefore, the $\mathrm{U}_{\text {turb,Full-Scale }}$ can be simplified to

$$
\mathrm{U}_{\text {turb }_{\text {Full_Scale }}}=1.3 \cdot \mathrm{R} \cdot \mathrm{U}_{\text {met }_{\text {Ful___cale }}}
$$

The energy generation of the wind turbines is heavily dependent on the combination of estimated full-scale wind speeds and the machine power curve of a specific type of wind turbine. In this study, a first-order total, or net, power approximation will be used to decide the accuracy of using wind-tunnel data. The power curve of the Kennetech 56-100 wind turbine was given in Eq. (3). The estimated total power for each cluster of wind turbines, at a specific meteorological tower, is found by summing the predicted power from each individual turbine:

$$
\left(P_{\text {total }}\right)_{\text {Wind_Tunnel }}=\sum_{i=1}^{N} P_{i}(U)
$$

where $\mathrm{P}_{\mathrm{i}}(\mathrm{U})$ is the estimated power at each projected full-scale wind-turbine wind speed, $\mathrm{U}_{\text {turb,Full-Scale, and } \mathrm{N}}$ is the total number of wind turbines for a given meteorological tower site.

The power industry standard is to record power production in units of kilowatt-hours (kW-hrs). However, the power prediction is in units of energy $(\mathrm{kW})$. This will be the standard used throughout this study. To make an accurate comparison of the actual energy to the estimated energy, Eq. (11) was refined to include a time interval. Since the Altamont turbine output data was recorded in the form of energy by summing the power in half-hour increments, the total energy becomes:

$$
\left(E_{\text {total-hrs }}\right)_{\text {Wind_Tunnel }}=\sum_{i=1}^{N} P_{i}(U) \cdot t_{\text {inc }} \cdot \frac{t_{\text {online }}}{t_{\text {available }}}
$$

where $\left(\mathrm{E}_{\text {total-hrs }}\right)_{\text {Wind-Tunnel }}$ is the estimated total energy output, $t_{\text {inc }}$ is the time increment of the meteorological data, which is 30 minutes in this study, $t_{\text {online }}$ is the time the wind turbines were connected to the power grid and producing power, and $t_{\text {available }}$ is the time the wind turbines were operational.

\section{Testing}

Measurements of the mean and RMS velocities, and turbulence intensities, were performed in the ABLWT to quantify the spatial variation of the local winds. Measurements were made at meteorological tower instrument heights, and turbine hub heights $7.6 \mathrm{~mm}(0.3$ in), $18.3 \mathrm{~m}$ (60 ft) full-scale or $10.2 \mathrm{~mm}(0.4 \mathrm{in}), 24.4 \mathrm{~m}$ $(80 \mathrm{ft})$ full-scale.) The wind-tunnel test simulated a wind blowing from $240^{\circ}$, the most common wind direction at the site. The majority of the powerproducing winds come from this direction. For turbines arranged in rows along ridge-tops, every other turbine location was measured. Values for unmeasured turbines were the average of the turbines on each side. Each location was sampled with the hot-wire probe for 90 seconds at a sampling frequency of $1000 \mathrm{~Hz}$. Each location was measured twice to ensure that average wind speed was repeatable within $0.15 \mathrm{~m} / \mathrm{s}$. The measured wind speeds were non-dimensionalized with a reference wind speed to get a wind-tunnel wind-speed ratio, $\mathrm{R}$.

Using Matlab, developed by Mathworks, a series of programs were written to estimate power production for each half hour period that production data was reported. The R-values from the tunnel, along with meteorological tower wind speed data from the met files, were used in Eq. (10) to estimate the full-scale 
wind speeds at the individual turbines. Power production of each turbine was calculated by applying the results of Eq. (10) to the power curve, Eq. (3). These results, and additional time information from the met data were incorporated into Eq. (12) to estimate the total power production of the turbine clusters associated with Meteorological Tower A and Meteorological Tower B. For complete details, see Cheng (2002). This

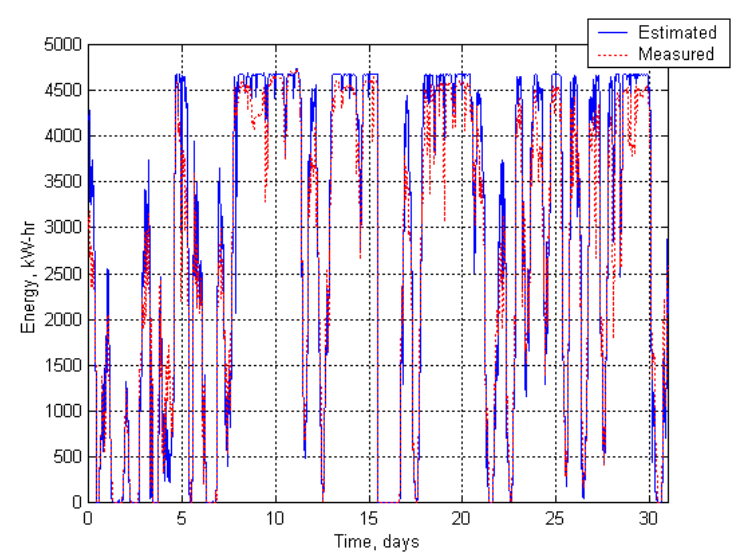

Fig. 7: Predicted versus actual power production for Tower A turbine cluster for July 2001.

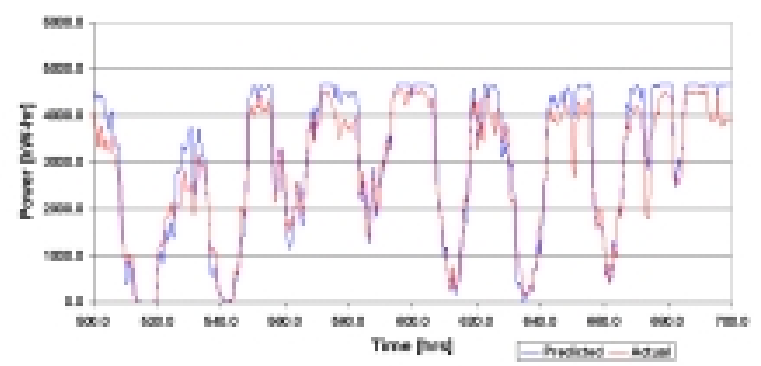

Fig. 8: Predicted versus actual power production for Tower A turbine cluster 8.3 days in July 2001.

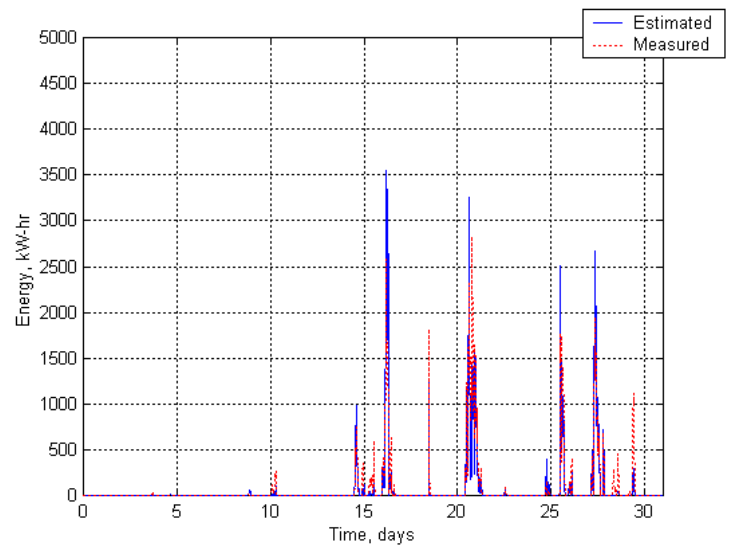

Fig. 9: Predicted versus actual power production for Tower A turbine cluster for Jan. 2002. allowed for direct comparison to the power production records from Powerworks, which are reported by turbine cluster on a half-hourly basis. Data was analyzed, and power predicted for the Metrological Tower A and Meteorological Tower B turbine clusters, in half hour intervals from July 2001 to June 2002.

\section{DISCUSSION AND RESULTS}

\section{Examining the Altamont Meteorological Data}

Wind-tunnel testing for this particular study was limited to one wind direction. Analysis of the Altamont site meteorological data indicated that $34 \%$ of the winds, including most of the high-speed power producing winds, occurred from the west-southwest direction, so the model was built to simulate a wind from $240^{\circ}$ true north. Seasonal variation was also observed in the wind patterns. It was observed that peak energy generation occurred during the summer, with high-wind speeds

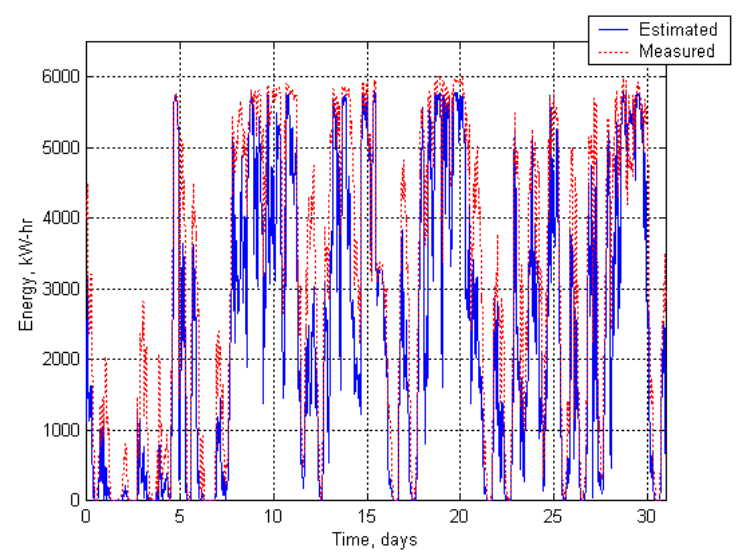

Fig. 10: Predicted versus actual power production for Tower B turbine cluster for July 2001.

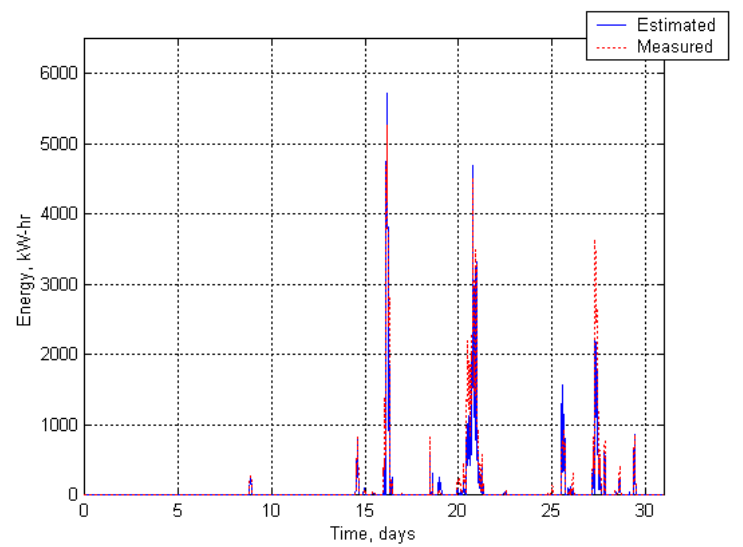

Fig. 11: Predicted versus actual power production for Tower B turbine cluster for Jan. 2002. 
and fairly constant wind directions. On average, energy output for $107,100 \mathrm{~kW}$ wind turbines for half-hour periods was approximately $2800 \mathrm{~kW}-\mathrm{hr}$, while wind direction was nearly constant at 240 degrees. The winter months were low-energy producing months with extremely variable wind speeds and wind directions. On average, energy output was no more than $180 \mathrm{~kW}$-hr with wind directions that varied daily. In the fall and spring, energy production fell in between the summer and spring levels with energy output of about $1200 \mathrm{~kW}$ $\mathrm{hr}$ with the direction of wind at about 212 degrees on most days. There is also a diurnal fluctuation in the site wind patterns. Due to the heating and cooling of the hills through the day, wind speeds generally were the highest in the early morning and late evening hours, with the winds tending to slow down in the middle of the day. The direction of the wind in the area is generally less variable than wind speed. Direction often changes 5 to 10 degrees from early morning to mid-day and changes back as day became evening.

\section{Estimation of Energy from Wind-Tunnel Testing}

Figs. 7 through 11 are examples of estimates of power production from the wind tunnel tests, compared to the recorded measurements from the Altamont meteorological tower data. Generally, the estimated power production for the Meteorological Tower A turbine cluster correlated better to the actual power production than the estimates for the Meteorological B cluster. This was attributed to the inability to test $30 \%$ of the Meteorological Tower B turbine cluster since these turbine sites were located off of the wind-tunnel model. To compensate, the total energy estimates were increased by $30 \%$ to account for the wind turbines that could not be tested. Even with this adjustment, the production was still significantly under-estimated from the measured energy production for Meteorological Tower B. This result suggests the value of wind tunnel testing. With Meteorological Tower A, all turbines in the cluster were tested and the correlation between the energy productions was good.

For Meteorological Tower A, power production was at times over-estimated using wind-tunnel data. However, in other instances, the energy production was underestimated. The best correlation was for the summer months, in which the wind speed and direction of the wind tend to be more constant. For example, from Fig. 12, the variation between estimated and measured energies were within $20 \%$ of the true value.

However, the variation between the estimated and measured energies increased to about $40 \%$ for the moderate power production seasons of fall and spring.

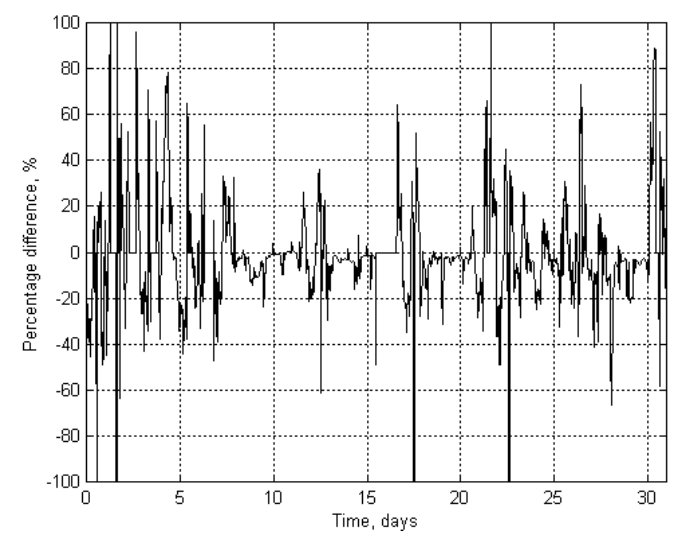

Fig. 12: Percent error between predicted and actual power production for Tower $A$ turbine cluster for July 2001.

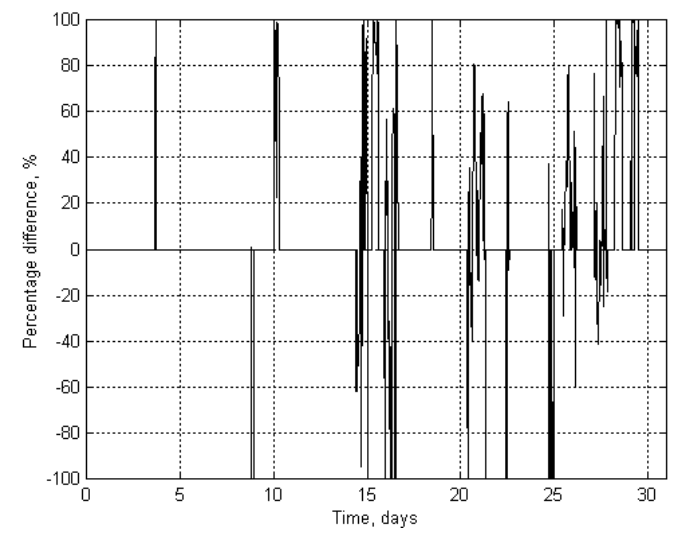

Fig. 13: Percent error between predicted and actual power production for Tower A turbine cluster for Jan. 2002.

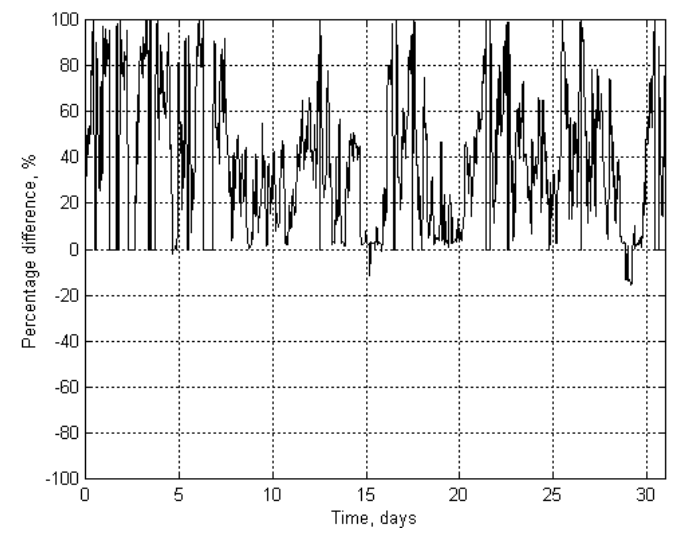

Fig. 14: Percent error between predicted and actual power production for Tower B turbine cluster for July 2001. 
In the winter season, it was much more difficult to determine the variations. At first, from Fig. 13, it appeared that the correlation was good. But upon closer inspection, wind speeds tended not to be high enough for wind energy production. Thus, the majority of comparisons were with zero wind speed.

For Meteorological Tower B, a uniform underestimation of power production was observed, as seen in Fig. 12. Again, this lack of agreement between the two sets of data was attributed to the inability to test $30 \%$ of the wind turbines locations on the model. Also, the cubic law relation between wind-speed and power makes wind power generation to be quite sensitive to minor changes in wind speed.

\section{Predicted vs. Observed Winds at Towers A and B}

The wind speeds observed at Towers A and B were compared for the period between July 1, 2001 and June 30,2002 . It was observed that the median wind speeds were $15.3 \mathrm{~m} / \mathrm{sec}$ at Tower A and $14.2 \mathrm{~m} / \mathrm{sec}$ at Tower B. The average ratio of Tower $\mathrm{A}$ wind speed over Tower B wind speed for the one year period was 1.19 , with a standard deviation of 0.36 , indicating that Tower A generally experiences stronger winds than Tower B.

The ratio of Tower A to Tower B wind speed was measured in the wind-tunnel as 1.0. It is believed that this variation is due to the wind-tunnel modeling neutral conditions, while often there are varying degrees of stable flow in the Altamont Pass. Table 1 gives the average ratio observed for different seasons, and at different three hour time intervals. It is not surprising that the wind-tunnel prediction of 1.0 is very close to the observed ratio between the hours of 15:00 to 18:00 local time (corresponding to hours 15-17 on table) during spring and summer. At these times, strong solar

\begin{tabular}{|c|c|c|c|c|}
\hline Hours & Winter & Spring & Summer & Fall \\
\hline $0-2$ & 1.249 & 1.178 & 1.351 & 1.231 \\
$3-5$ & 1.299 & 1.166 & 1.275 & 1.217 \\
$6-8$ & 1.224 & 1.143 & 1.206 & 1.242 \\
$9-11$ & 1.189 & 1.081 & 1.179 & 1.153 \\
$12-14$ & 1.178 & 1.077 & 1.133 & 1.122 \\
$15-17$ & 1.306 & 1.063 & 1.069 & 1.173 \\
$18-20$ & 1.269 & 1.113 & 1.138 & 1.297 \\
$21-23$ & 1.167 & 1.187 & 1.304 & 1.222 \\
\hline
\end{tabular}

Table 1: Average ratios of Tower A wind speed over Tower B wind speed. Field data observed between July 1, 2001 and June 30, 2002, for three hour blocks of time. Wind-tunnel prediction for ratio was 1.0. heating of the surface would be expected to have produced locally neutral or unstable conditions much of the time. Conversely, larger discrepancies are observed during night periods, and the fall and winter seasons, when cool surface conditions would be expected to produce strongly stable flows most of the time.

This discrepancy between actual and wind-tunnel ratios of the average wind speeds during stable periods would be expected to produce an over-prediction of the power output of the Tower B cluster if the Tower A prediction is taken as accurate. However, under-prediction of the Tower B production relative to Tower A was actually observed in this study. This suggests that the error introduced by not modeling $30 \%$ of the turbines contributed to a large enough under-prediction bias that it more than cancelled out the over-prediction due to stability that would be expected because of the model over-predicting the wind speed at Tower B.

\section{Sensitivity of Power Prediction to Wind Speed}

A sensitivity analysis was performed to determine the effect of wind speed on power production, using the power curve defined in Eq. (3). An arbitrary mean wind speed of $10 \mathrm{~m} / \mathrm{s}$ was selected for the energy production comparison. For the first comparison group, a change in the mean wind speed of $\pm 0.1 \mathrm{~m} / \mathrm{s}$ produced a change of energy generation by $\pm 3 \%$. With a change of mean wind speed of $\pm 0.5 \mathrm{~m} / \mathrm{s}$, the difference in energy was \pm $15 \%$. Finally, at $\pm 1 \mathrm{~m} / \mathrm{s}$ difference of wind speed, energy production varied by $\pm 30 \%$. This analysis indicates that even with fairly accurate estimation of wind speed, the predicted power generation can vary significantly due to small uncertainty in wind speeds.

\section{CONCLUSIONS}

A wind-tunnel model of the terrain around two wind farms was tested at the UC Davis Atmospheric Boundary Layer Wind-Tunnel. In general, the boundary layer wind-tunnel is an effective way to simulate turbulent characteristics of full-scale steady winds at neutral atmospheric conditions. Wind-tunnel measurements, using a hot-wire anemometer, were conducted at model wind-turbine hub height. The measurements from the wind tunnel were converted to full-scale conditions and applied to the machine power curve of the Kennetech 56-100 wind turbines. Meteorological data from July 2001 to June 2002 was used to predict power production of two clusters of wind turbines every half hour for a one-year period. The resulting wind-tunnel estimated power production was compared to the actual power production of the 
turbine clusters and showed reasonably good agreement.

It was determined that estimated power production for the Meteorological Tower A turbines were within $20 \%$ of the true value for summer months and within $40 \%$ in the fall and spring. At first glance, it would appear that estimates were less than accurate, but doing a rudimentary sensitivity analysis, it was found that a $20 \%$ difference in estimated energy represented differences of estimate wind-speeds to actual windspeeds of around $0.5 \mathrm{~m} / \mathrm{s}$. With a $40 \%$ difference in energy output, the wind-speed variation was approximately $1.0 \mathrm{~m} / \mathrm{s}$. This phenomenon was due to the cubic law relation between wind-speed and turbine power production.

The wind-tunnel results of the Meteorological Tower B turbines showed a uniform under-estimation of power production when compared to the actual recorded power production. This was attributed to the fact that only $70 \%$ of the wind-turbine cluster could be modeled, and that adding $30 \%$ to production estimates was insufficient to achieve accurate predictions.

Comparison of observed field data to wind-tunnel measurements for the two meteorological towers confirmed that wind speed distributions predicted using the wind-tunnel data were most accurate during neutral or unstable conditions, with reduced accuracy occurring when stable conditions would be expected to occur.

Overall, the wind-tunnel results were deemed reasonable and effective in modeling of the full-scale conditions experienced by a wind-turbine cluster.

\section{ACKNOWLEDGMENTS}

The authors wish to thank Chuck McGowin, Electric Power Research Institute (EPRI), and Bob Szymanski, PowerWorks Inc., for supplying the necessary meteorological and wind-turbine data to make this project possible. This work was supported by a grant from the EPRI California Wind Energy Forecasting Project (EPRI Agreement EP-P2101/C924; "California Wind Energy Forecasting Program Wind Tunnel Testing: UC Davis"). The support from George Simmons, Dora Yen-Nakafuji and Michael Kane, all of the California Energy Commission, is gratefully acknowledged.

\section{REFERENCES}

Barnard, J., Wegley, H., Hiester, T. Improving the Performance of Mass-Consistent Numerical Models Using Optimization Techniques. J. of Climate and Applied Meteorology, vol. 26, no. 6, pp. 675-686. 1987.

Barnard, J. An Evaluation of Three Models Designed For Siting Wind Turbines in Areas of Complex Terrain. Solar Energy, vol. 46, no. 5, pp. 283-294. 1991.

Brown, A., Watt, J. The Design and Construction of 25 MW Wind Farm. Journal of Wind Engineering and Industrial Aerodynamics, vol. 27, no. 1-3, pp. 319-325. 1988.

Chapman, R. K. and Gouveia, F. J., Building III Wind Flow Study: July 1987, Lawrence Livermore National Laboratory, Livermore, California, 1987.

Cheng, J., Wind Energy Forecasting of a Wind Turbine Farm in the Altamont Pass Through Wind Tunnel Modeling, Master's Thesis, University of California, Davis, 2002.

Counihan, J., Adiabatic Atmospheric Boundary Layer: A Review and Analysis of Data From the Period 18801972, Atmos. Env., vol. 9, no. 10, pp. 871-905, 1975.

Davenport, A.G., The application of statistical concept of wind loading of structures, Proceedings of the Institution of Civil Engineering, 19, pp. 449-472, 1961.

Davis, E., Nierenberg, R. Wind Prospecting in Alameda and Solano Counties: Volume 1. Pacific Gas and Electric Company. Consultant Report to California Energy Commission (P500-80-054). May, 1980.

EPRI Technical Report 1007338. California Wind Energy Forecasting System Development and Testing. Phase 1: Initial Testing, Palo Alto, CA, USA, January 2003(a).

EPRI Technical Report 1007339. California Wind Energy Forecasting System Development and Testing. Phase 2: 12-Month Testing, Palo Alto, CA, USA, July 2003(b).

Holets, S. H. Wind Speed Variability in the California Altamont Pass Area. AWEA Windpower '85 Conference Proceedings, pp. 411-416. San Francisco, CA, USA, Aug. 27-30, 1985. 
Jensen, M., The Model-Law for Phenomena in a Natural Wind, Ingenioren, Int. Ed., vol. 2, no. 4,1958.

McCarthy, E. F. Stably Stratified Flow in Altamont Pass. U.S. Windpower, Inc. May 15, 1987. Personal communication.

McGowin, Charles R. and Pantoya, Michelle L. California Wind Energy Forecasting Project, Electric Power Research Institute, Palo Alto, California, 1999.

Miller, C. A. and Davenport, A. G. Guidelines for the Calculation of Wind Speed-Ups in Complex Terrain. J. Wind Engineering and Industrial Aerodynamics, 74-76 pp.189-197, 1998.

Nierenberg, R. D. Macro-Scale Wake Effects. AWEA Windpower ' 89 Conference Proceedings, pp. 14-19. San Francsico, CA, USA, Sept. 24-27, 1989.

Snyder, William H., Guideline For Fluid Modeling of Atmospheric Diffusion, U.S. Environmental Protection Agency, Research Triangle Park, North Carolina, 1981.

White, Bruce R., Analysis and wind tunnel simulation of pedestrian-level winds in San Francisco, Journal of Wind Engineering and Industrial Aerodynamics, 41-44, pp. 2353-2364, 1992.

White, Bruce R. and Cheng J., California Wind Energy Forecasting Program Wind Tunnel Testing: UC Davis, Electric Power Research Institute, Final Report, Contract EP-P2101/C924, 2002. 